\title{
Synthesis of Perfluoro[2.2]paracyclophane
}

William R. Dolbier, Jr., ${ }^{*}$ Puhui Xie, Lian Hao Zhang, Wei Xu, Ying Chang and Khalil A. Abboud

Department of Chemistry, University of Florida, Gainesville, FL 32611-7200

\section{Supporting Information}

\section{Contents}

General experimental methods

X-Ray experimental

ORTEP drawing of F8

NMR spectra

$1 \quad{ }^{19} \mathrm{~F}$

${ }^{13} \mathrm{C}$

$2{ }^{19} \mathrm{~F}$

$3 \quad{ }^{1} \mathrm{H}$

${ }^{19} \mathrm{~F}$

${ }^{13} \mathrm{C}$

$4{ }^{1} \mathrm{H}$

${ }^{19} \mathrm{~F}$

$5 \quad{ }^{1} \mathrm{H}$

$6{ }^{19} \mathrm{~F}$
S2

S2

S3

S4-S24

S4-S6

S7

S8

s9

$\mathrm{S} 10$

S11

S12-S13

S14

$\mathrm{S} 15$

$\mathrm{S} 16$ 


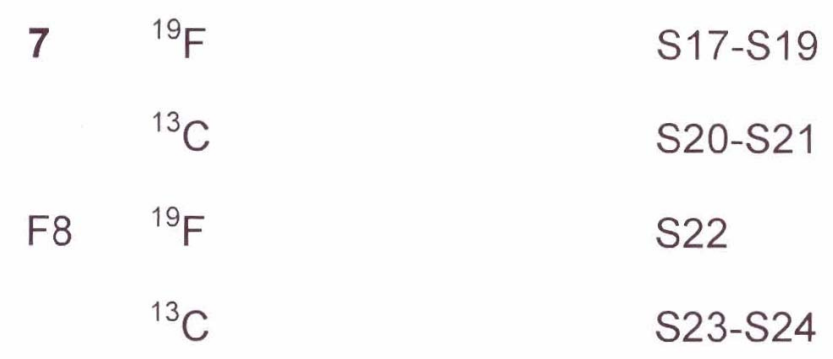

General Experimental Methods. Unless otherwise specified, proton, carbon and fluorine $\mathrm{NMR}$ spectra were obtained in $\mathrm{CDCl}_{3}$ at $300,75.5$ and $282 \mathrm{MHz}$, respectively, and chemical shifts are reported upfield relative to TMS for proton and carbon, and relative to $\mathrm{CFCl}_{3}$ for fluorine NMR.

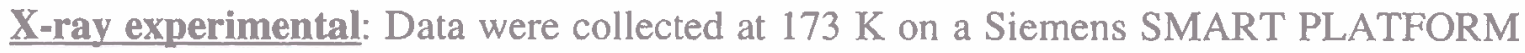
equipped with $\mathrm{A} C \mathrm{CD}$ area detector and a graphite monochromator utilizing $\mathrm{MoK}_{\alpha}$ radiation $(\lambda$ $=0.71073 \AA$ ). Cell parameters were refined using up to 8192 reflections. A full sphere of data (1850 frames) was collected using the $\omega$-scan method $\left(0.3^{\circ}\right.$ frame width). The first 50 frames were re-measured at the end of data collection to monitor instrument and crystal stability (maximum correction on I was $<1 \%$ ). Absorption corrections by integration were applied based on measured indexed crystal faces.

The structure was solved by the Direct Methods in SHELXTL6,' and refined using fullmatrix least squares. The non- $\mathrm{H}$ atoms were treated anisotropically, whereas the hydrogen atoms were calculated in ideal positions and were riding on their respective carbon atoms. The asymmetric unit consists of two half molecules with each molecule located on an independent center of inversion. A total of 289 parameters were refined in the final cycle of refinement using 8928 reflections with $\mathrm{I}>2 \sigma(\mathrm{I})$ to yield $\mathrm{R}_{1}$ and $w \mathrm{R}_{2}$ of $3.50 \%$ and $9.05 \%$, respectively. Refinement was done using $\mathrm{F}^{2}$. 
ORTEP Drawing from X-ray crystal structure determination

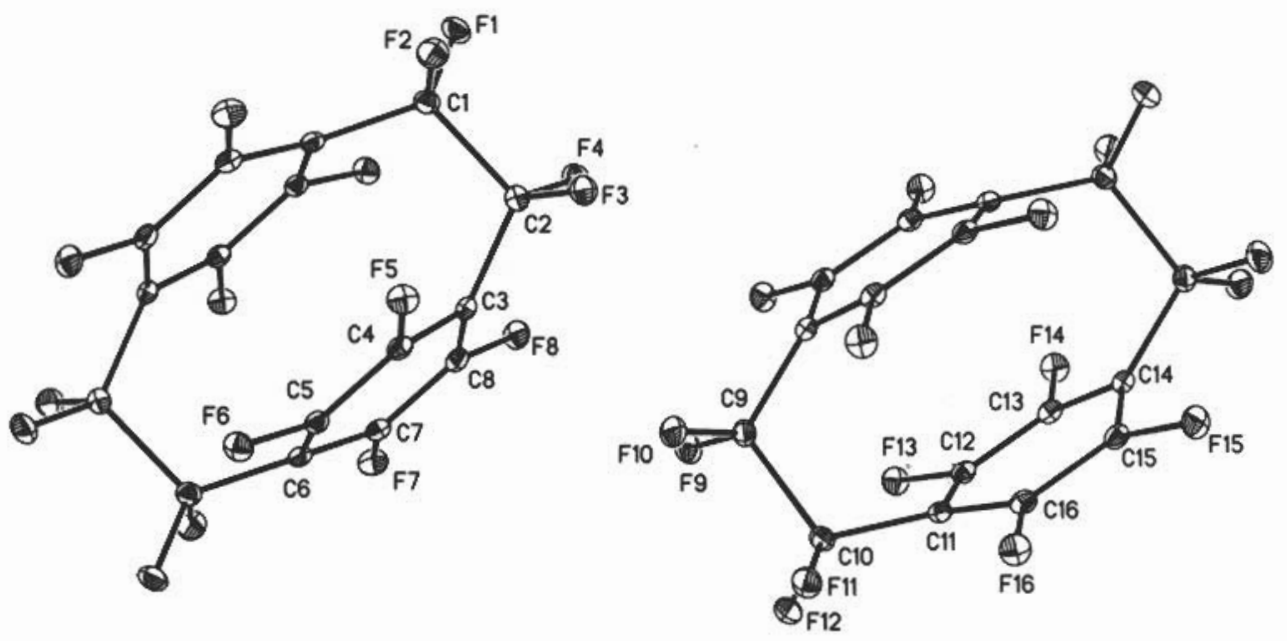

(1) SHELXTL6 (2000). Bruker-AXS, Madison, Wisconsin, USA. 


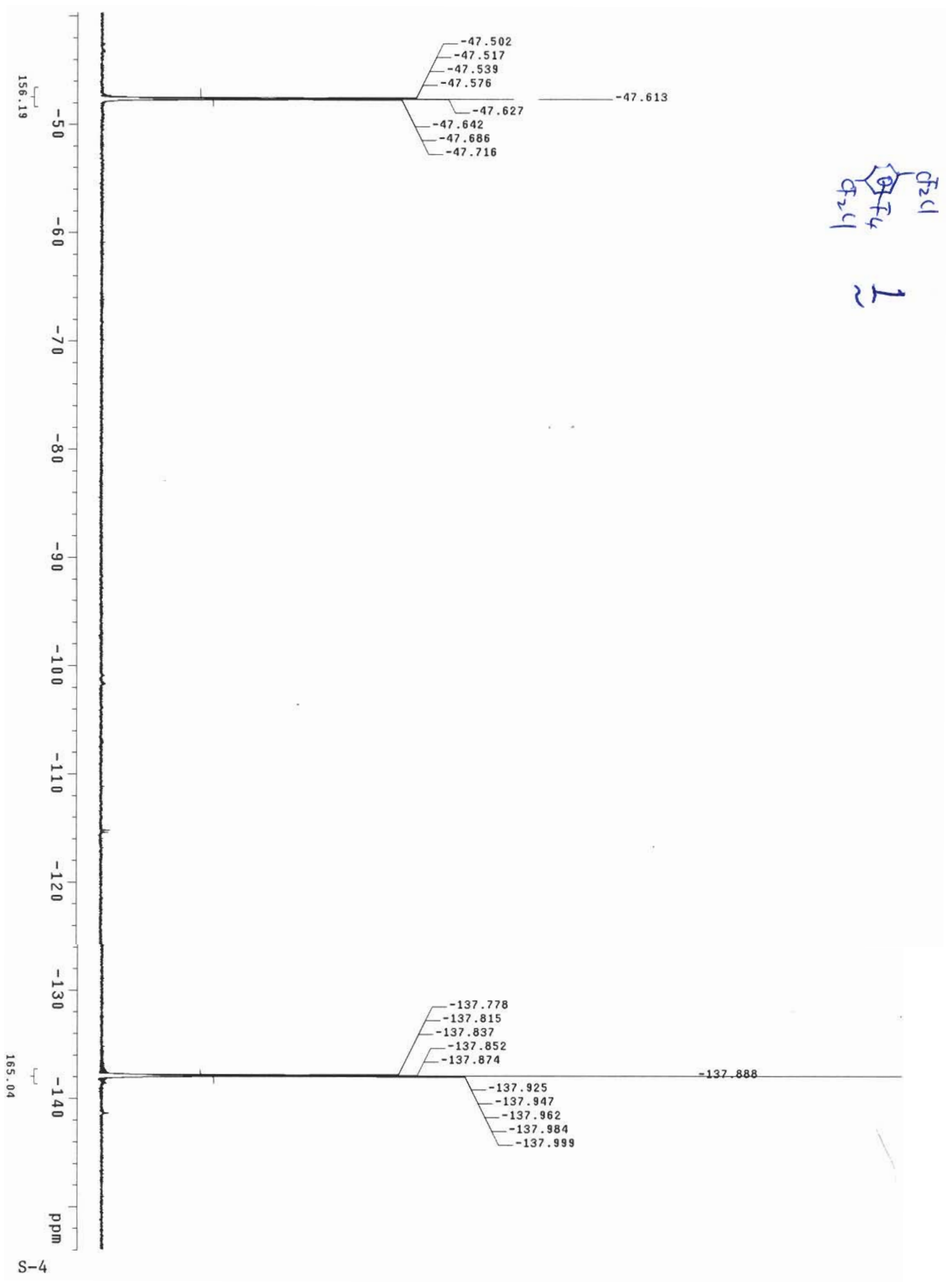




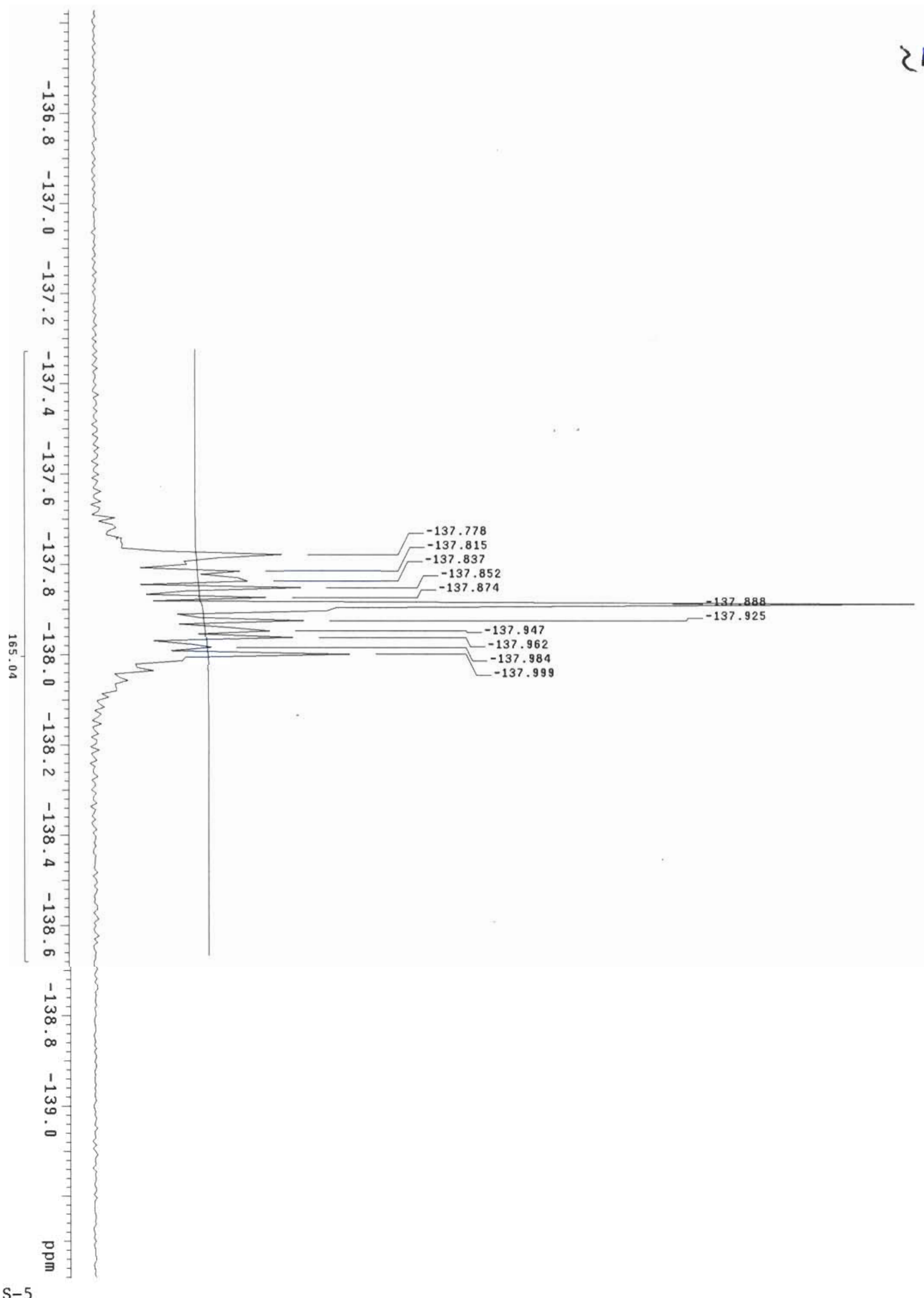


$\underset{-1}{-1}+2$

N

$\stackrel{1}{b}$

के

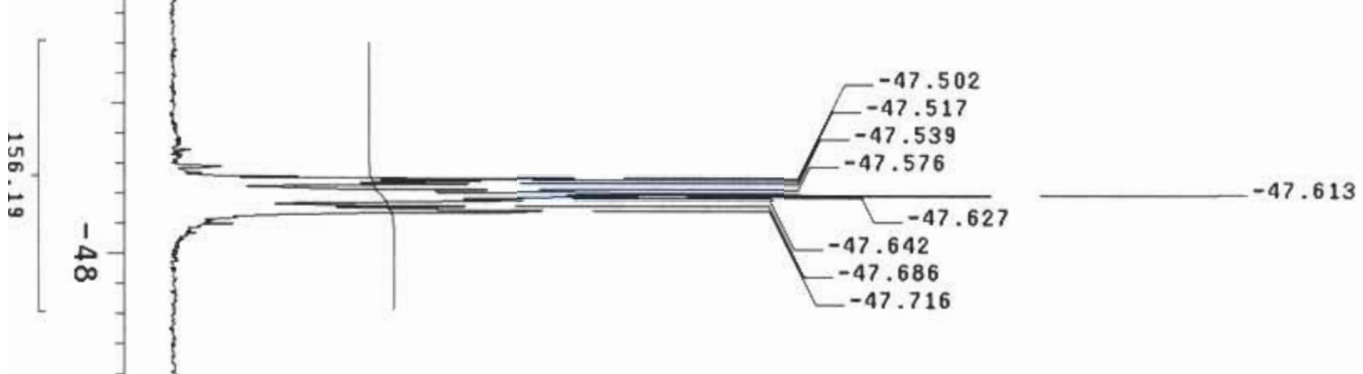

뭅

N

ज́

$\stackrel{1}{\Delta}$

-

- 


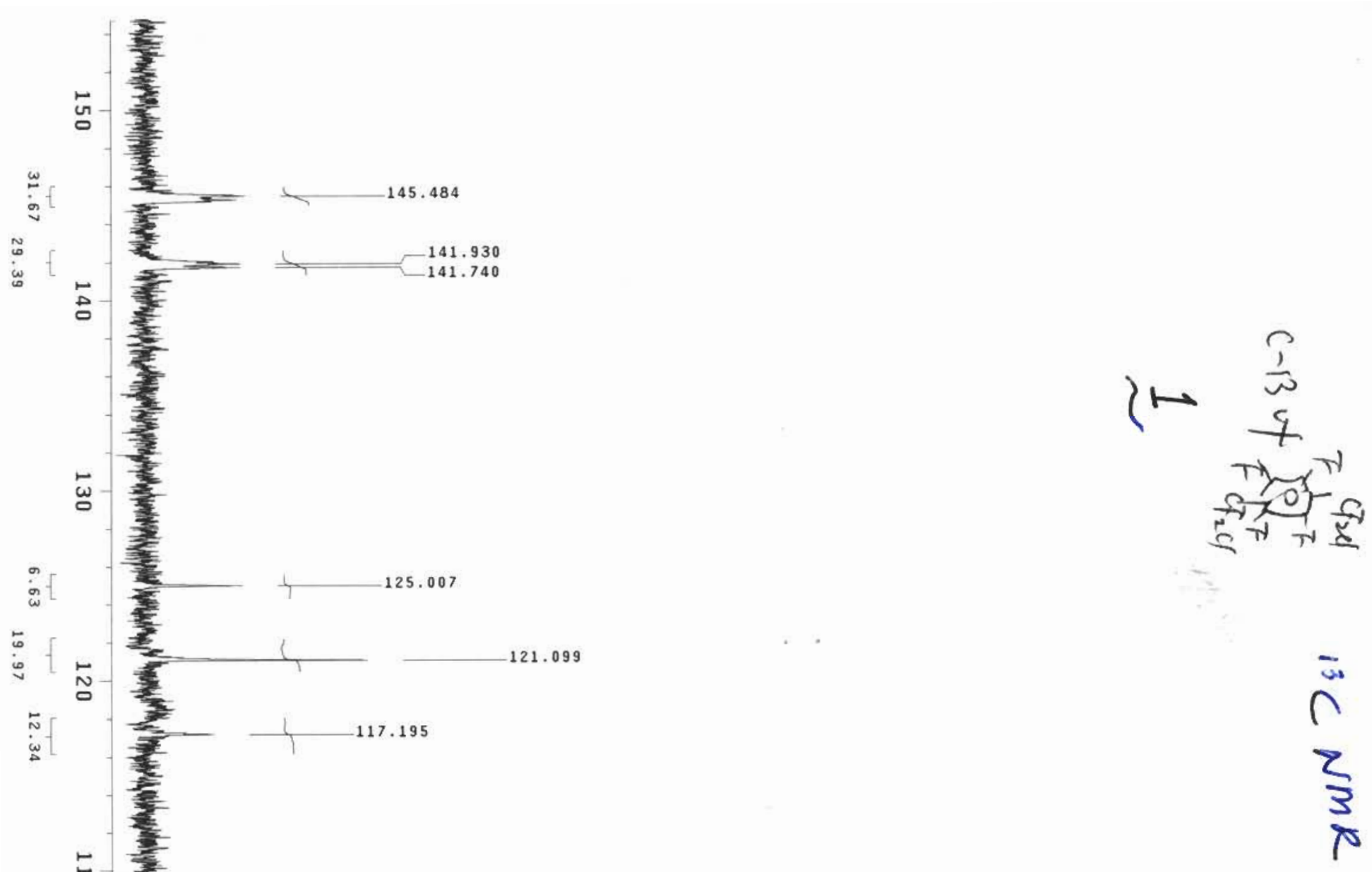

$\stackrel{\infty}{\circ}$

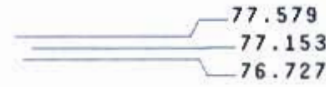

ㅁ

뮵 竞 

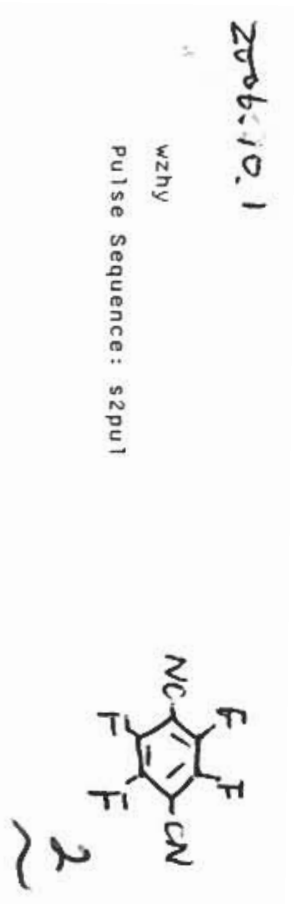

in

$\stackrel{1}{\circ}$

$\frac{\pi}{\pi}$

$\frac{z}{5}$

点

号

$-128.536$

N

듬

S-8 

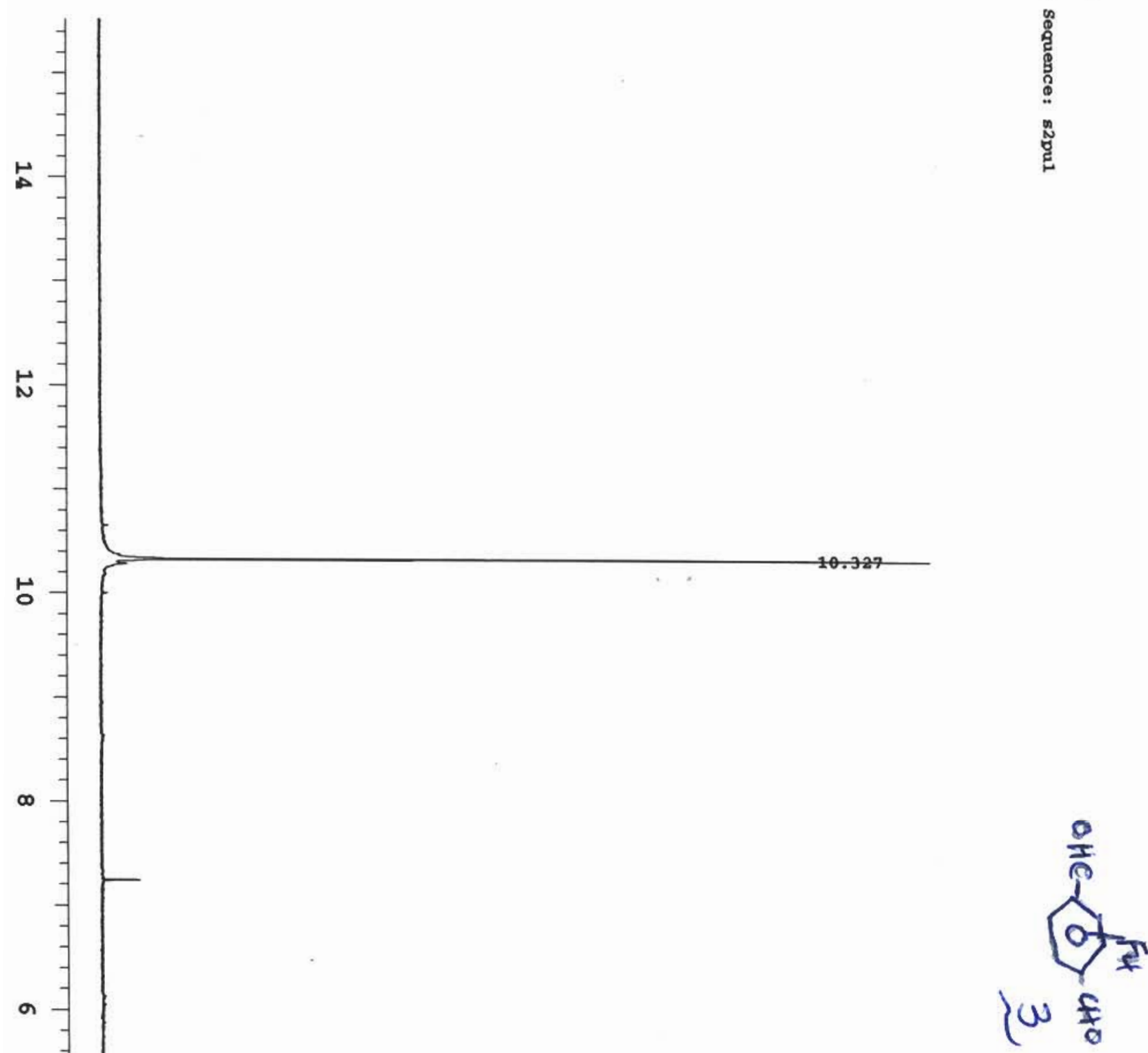

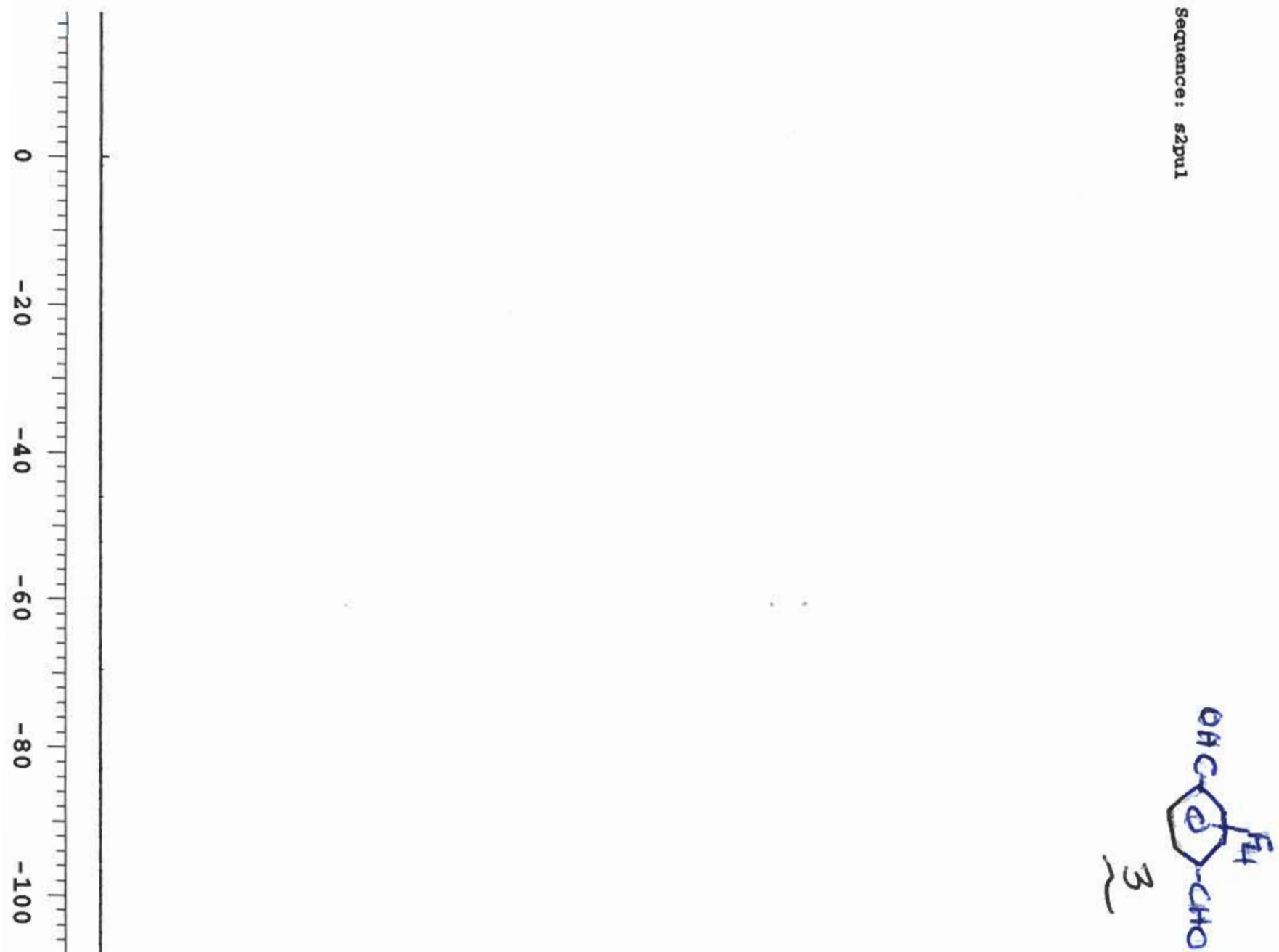


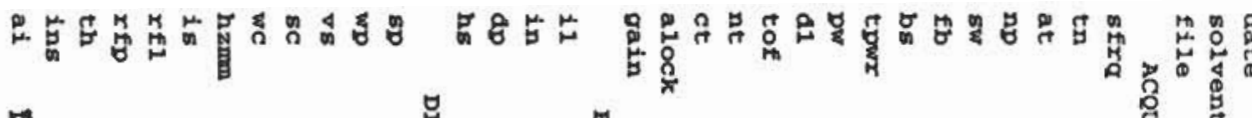

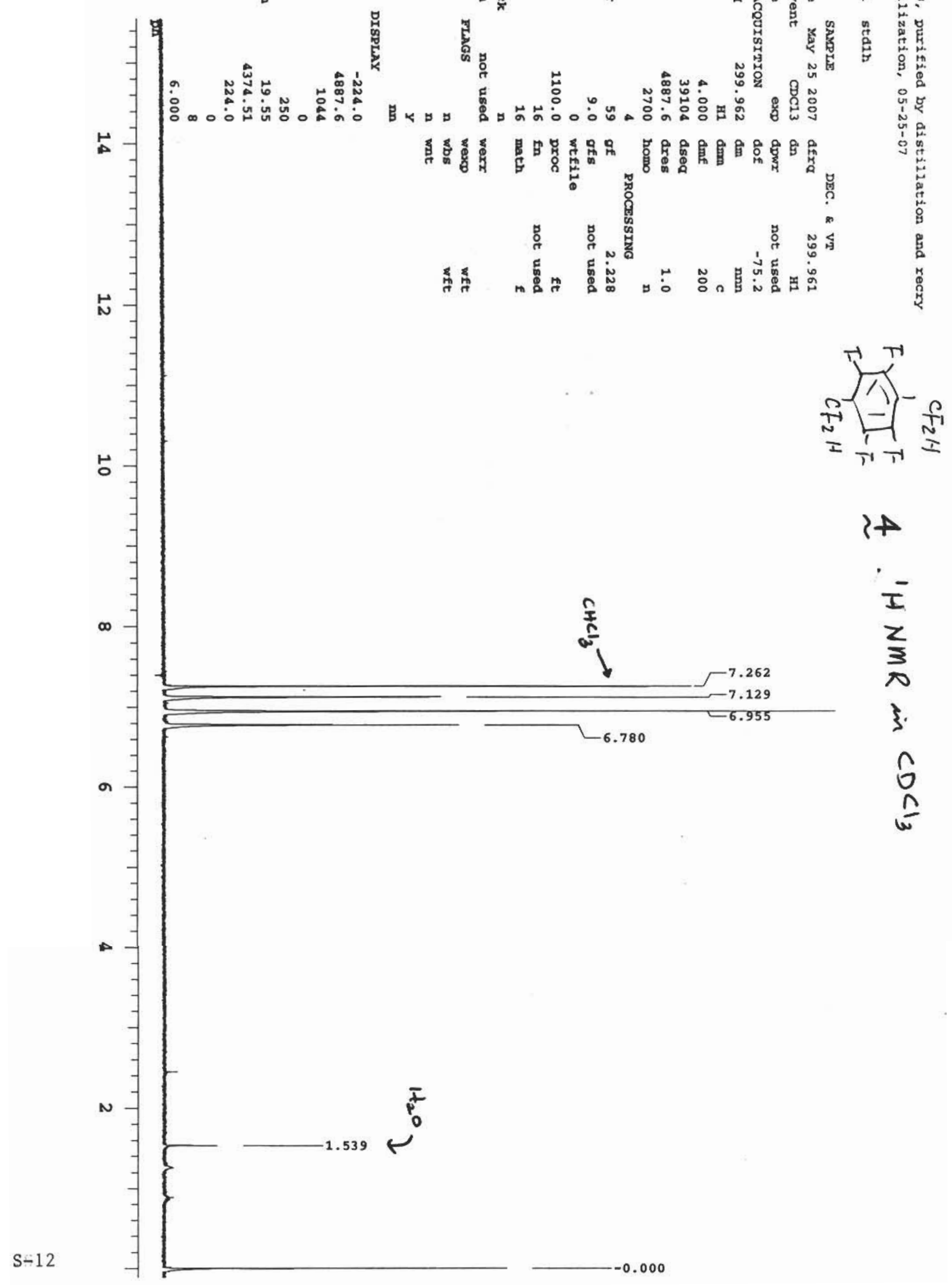




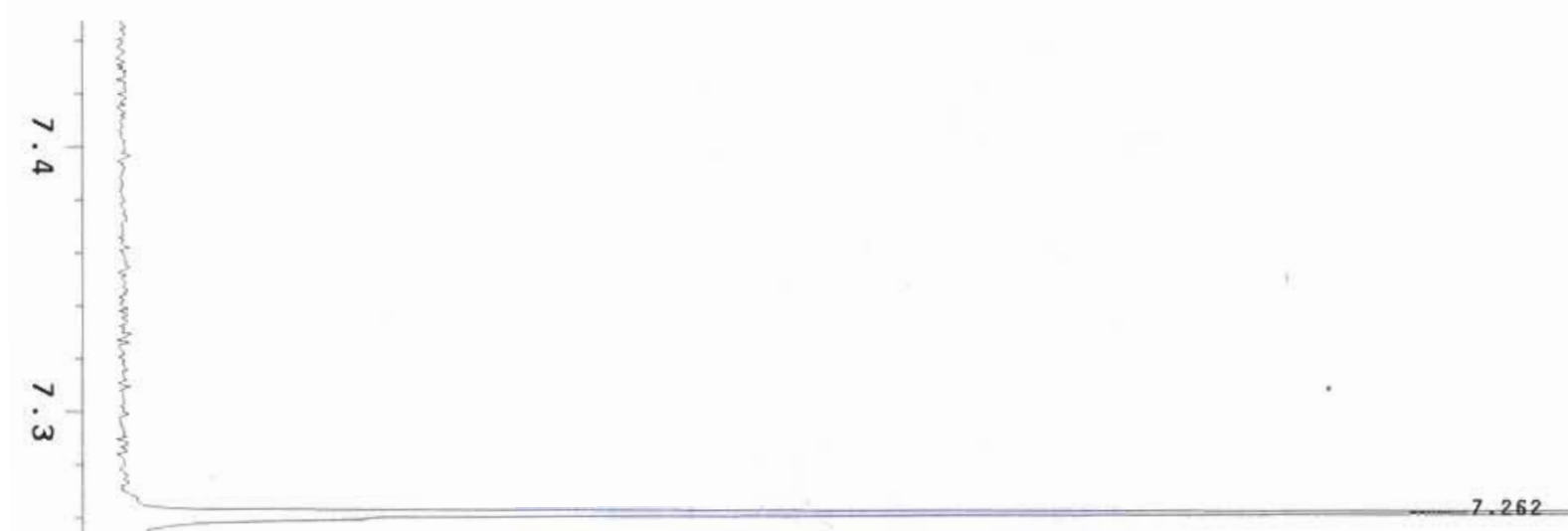

$-7.123$

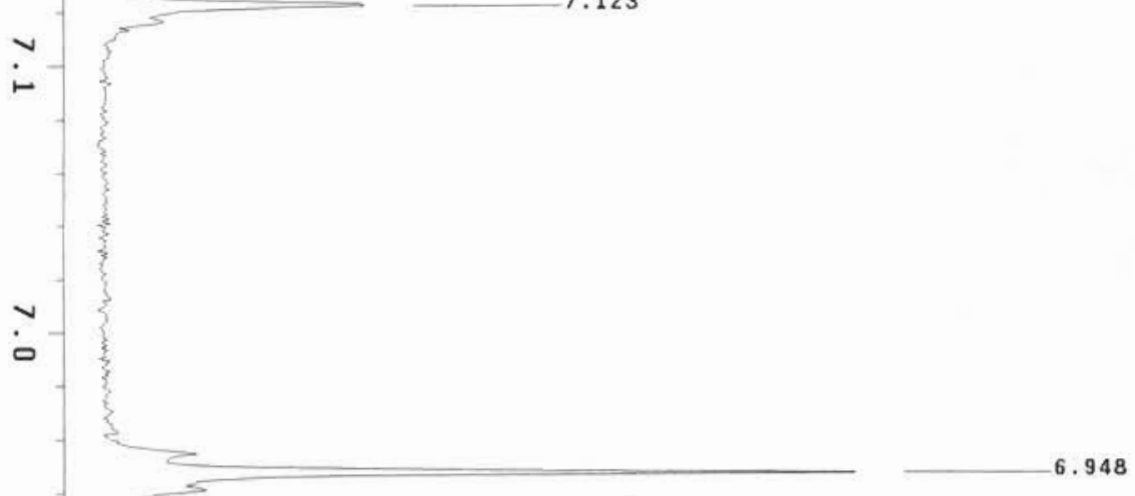

$-6.773$

का

ס

क

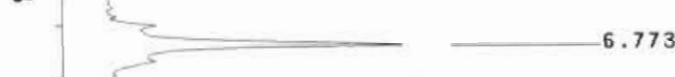

믑

S-13 


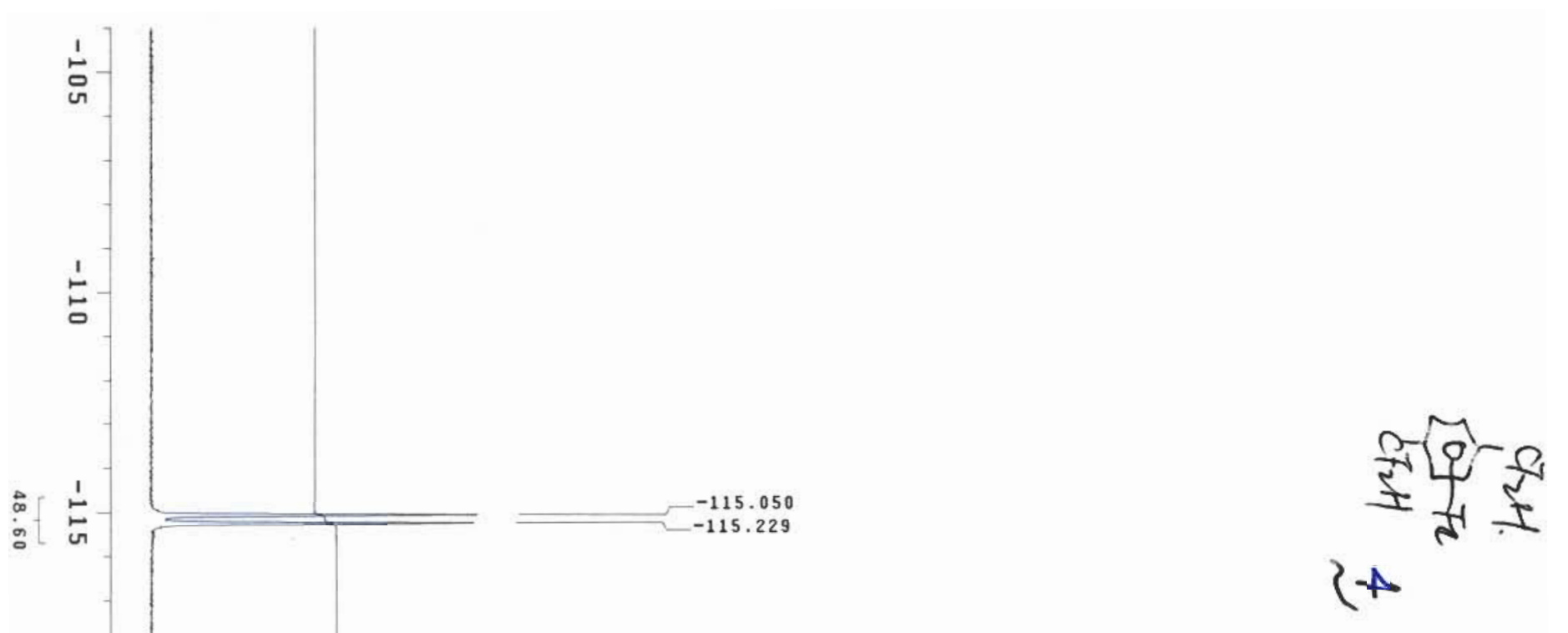




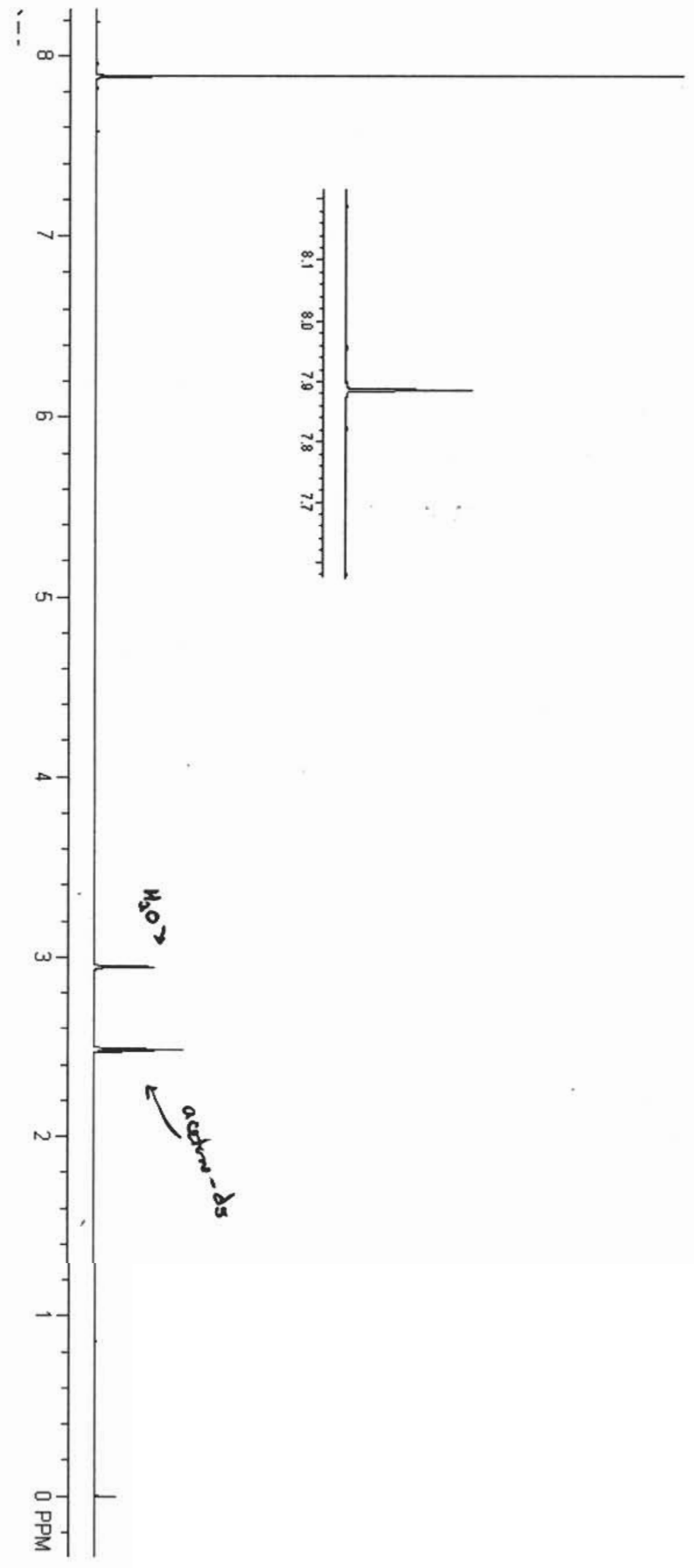

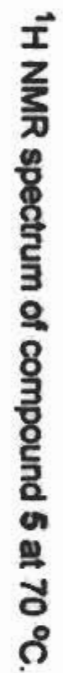

S-15 


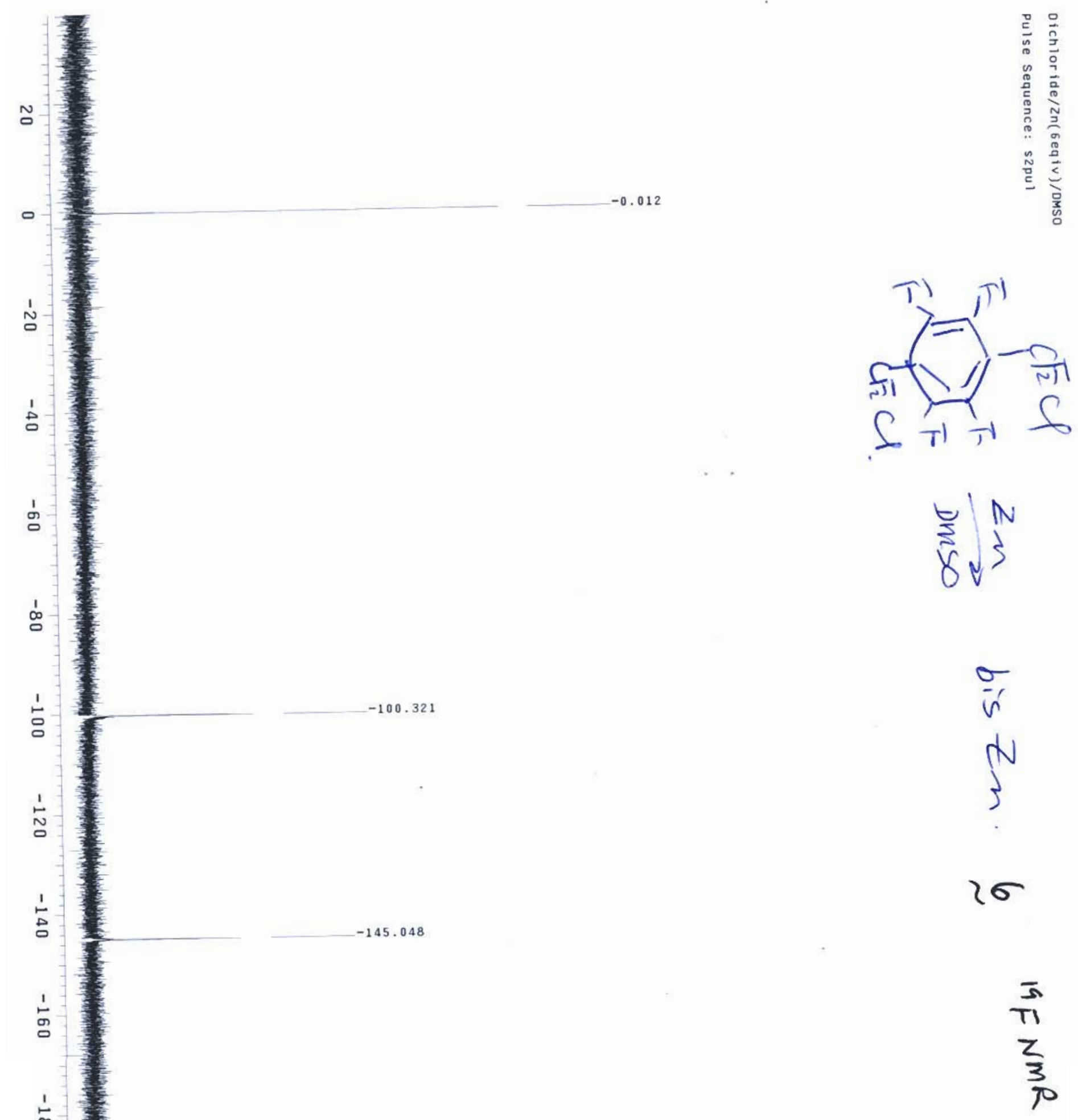




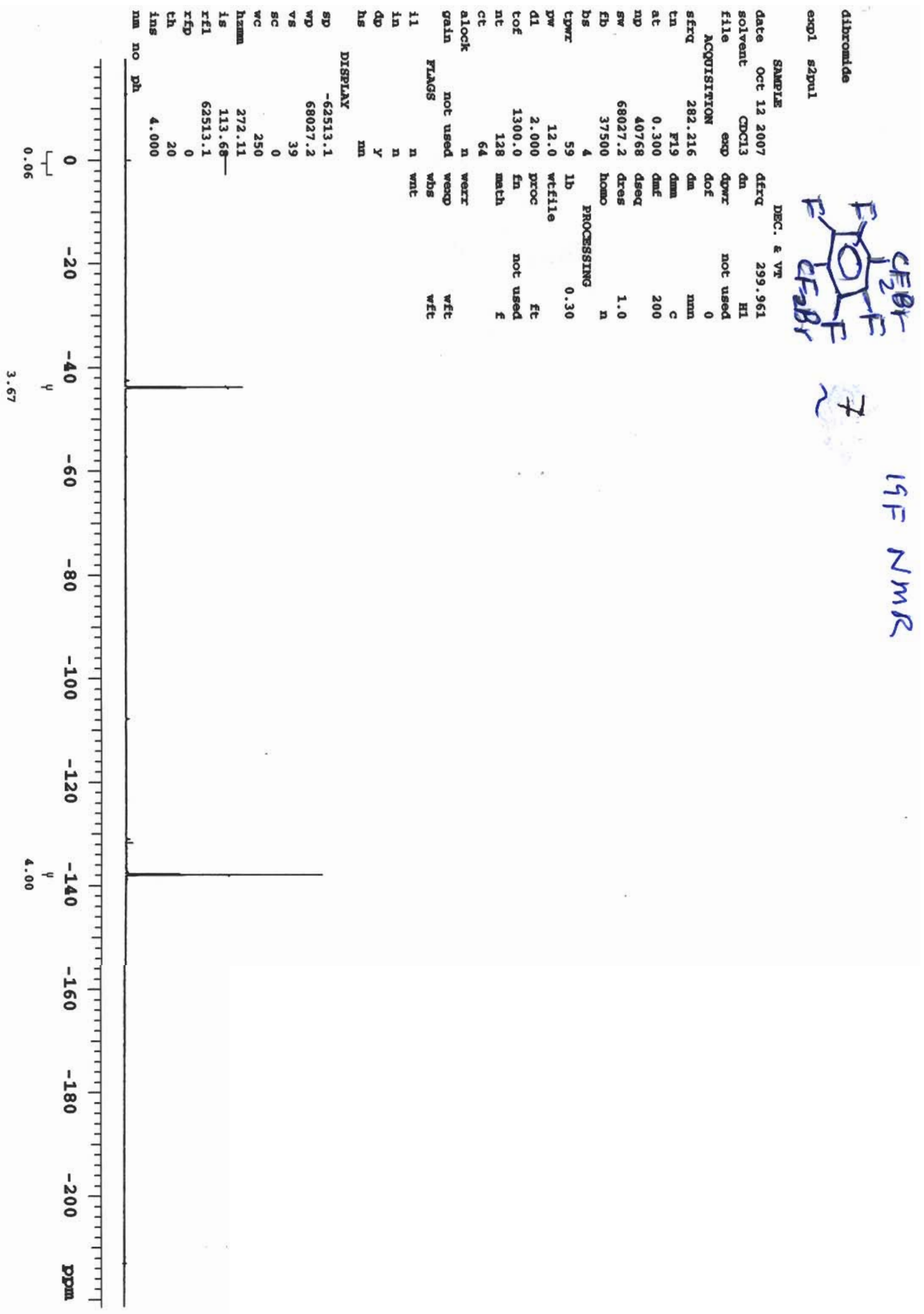




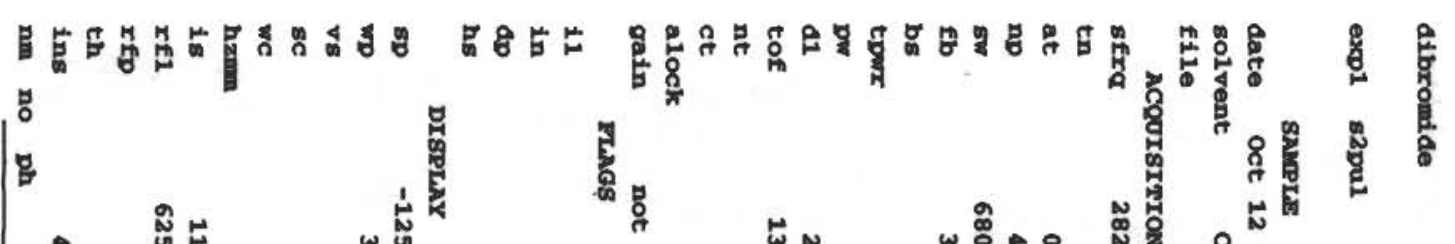

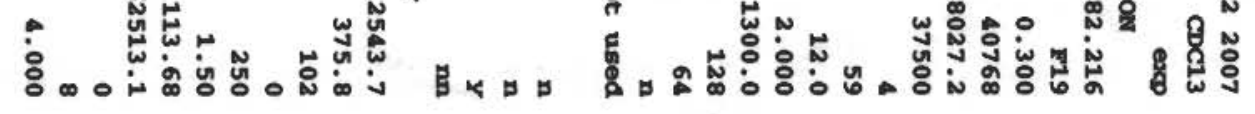

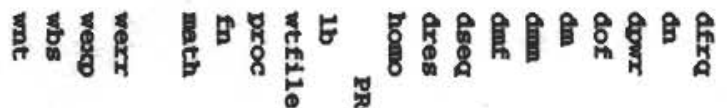

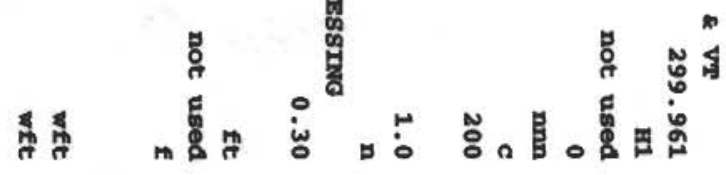

.

i

$\left[\begin{array}{c}1 \\ b\end{array}\right.$ 


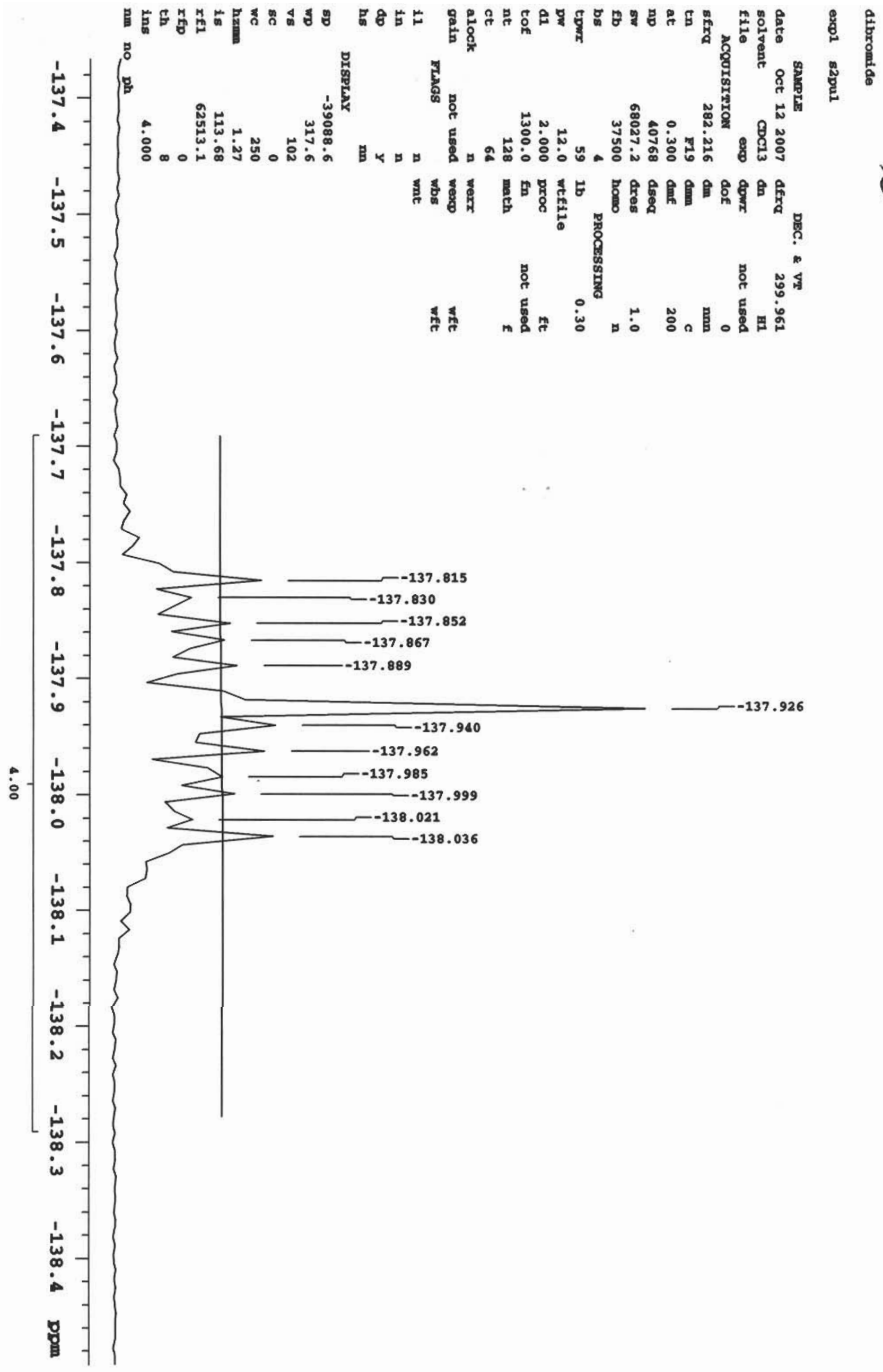




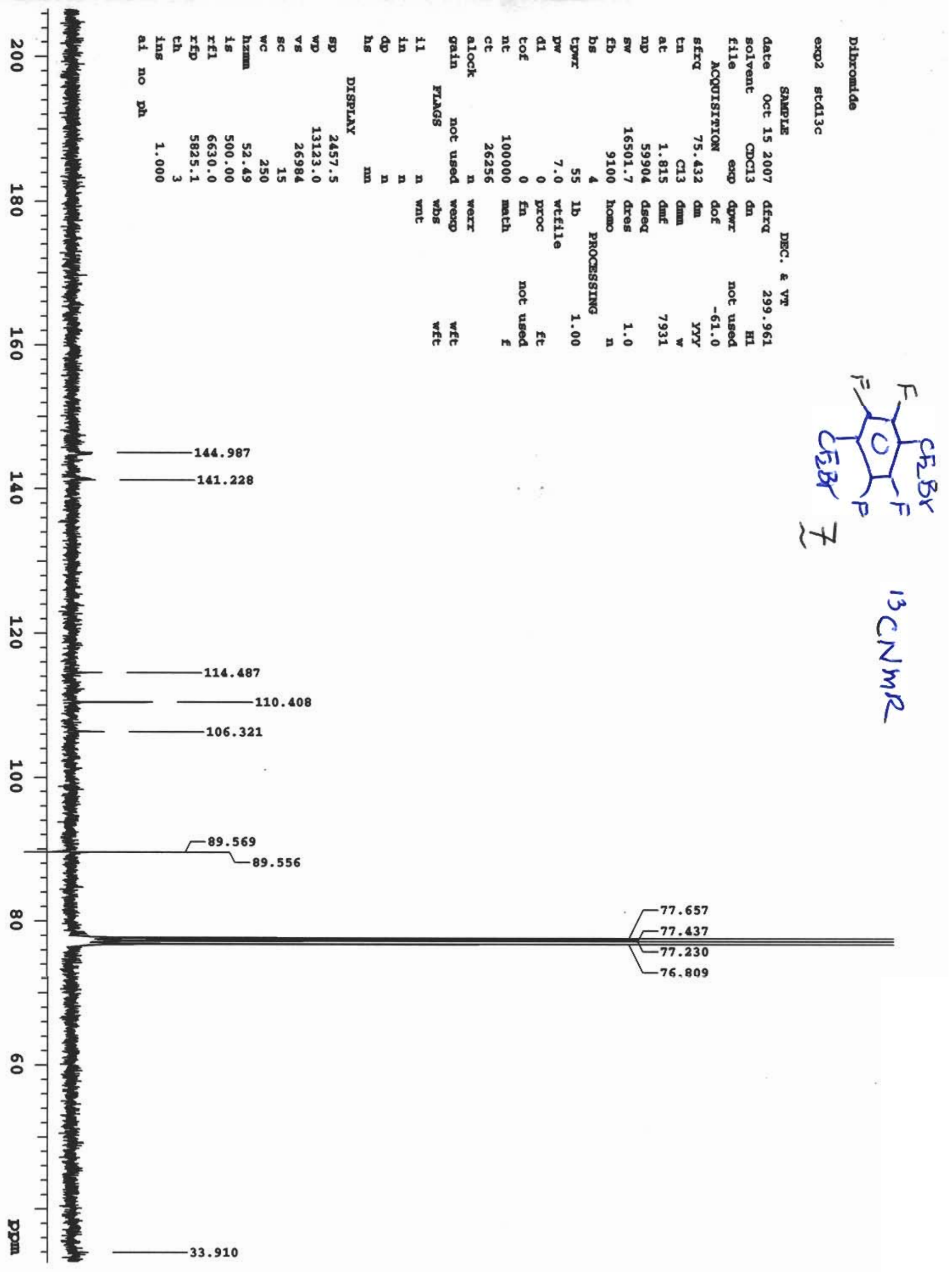




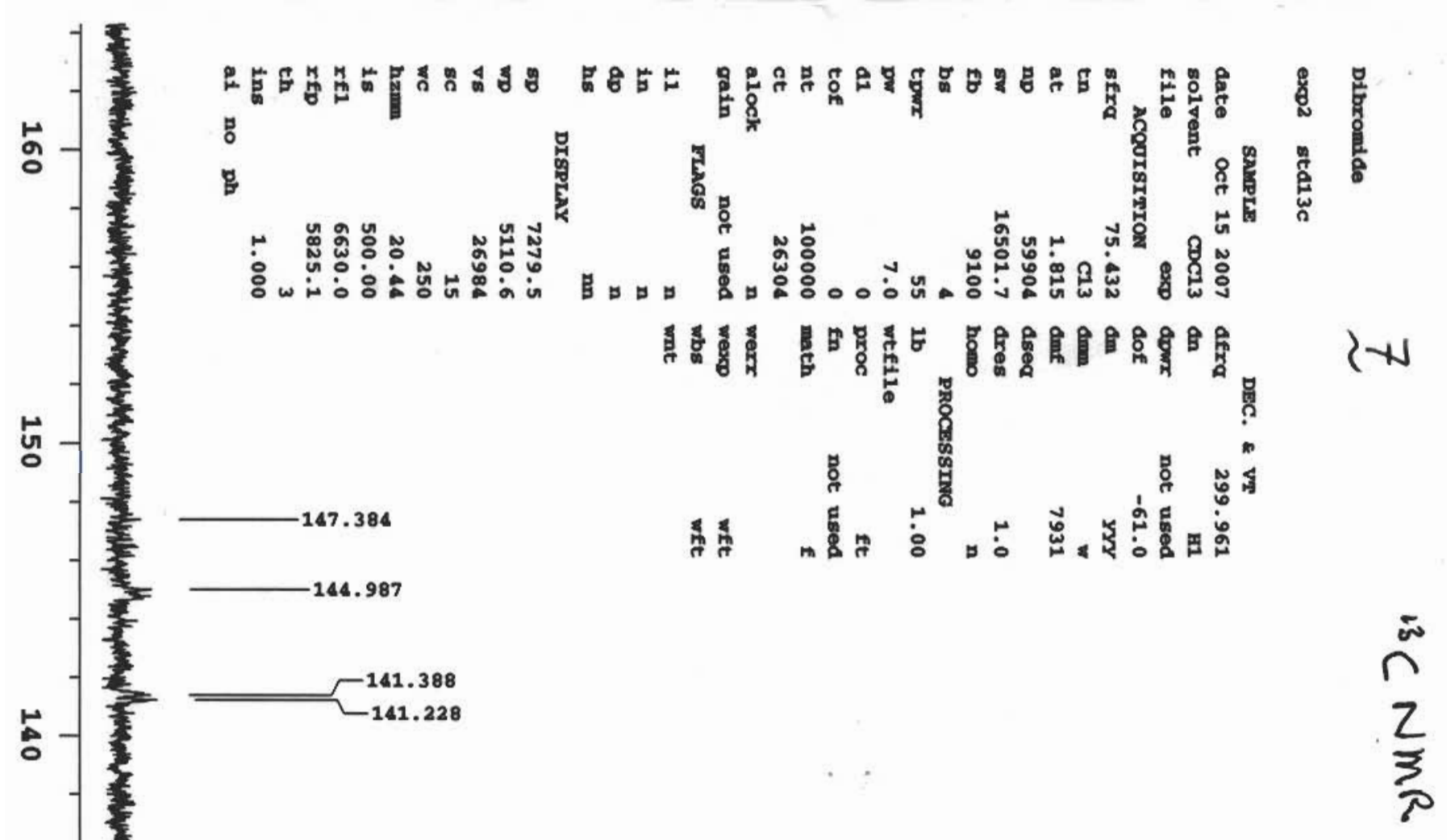

๘

w

농

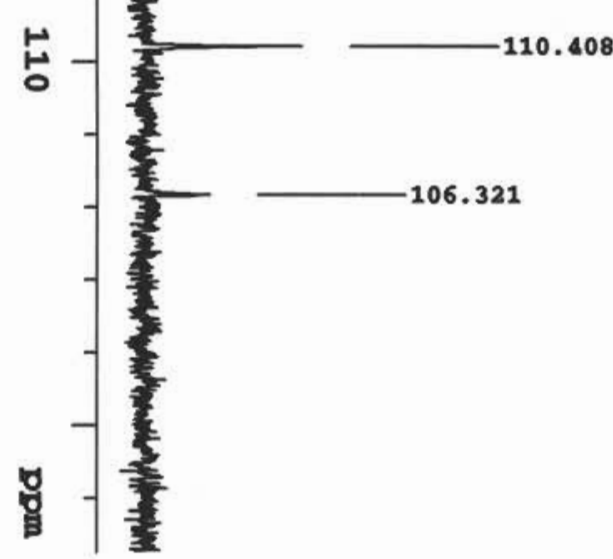




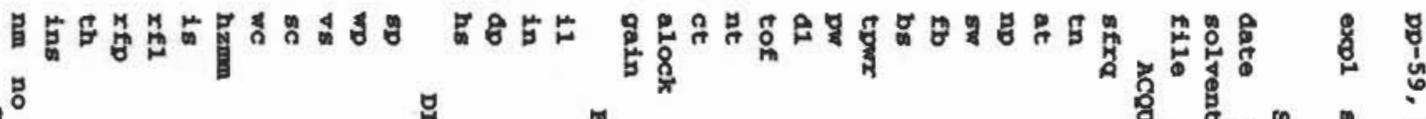

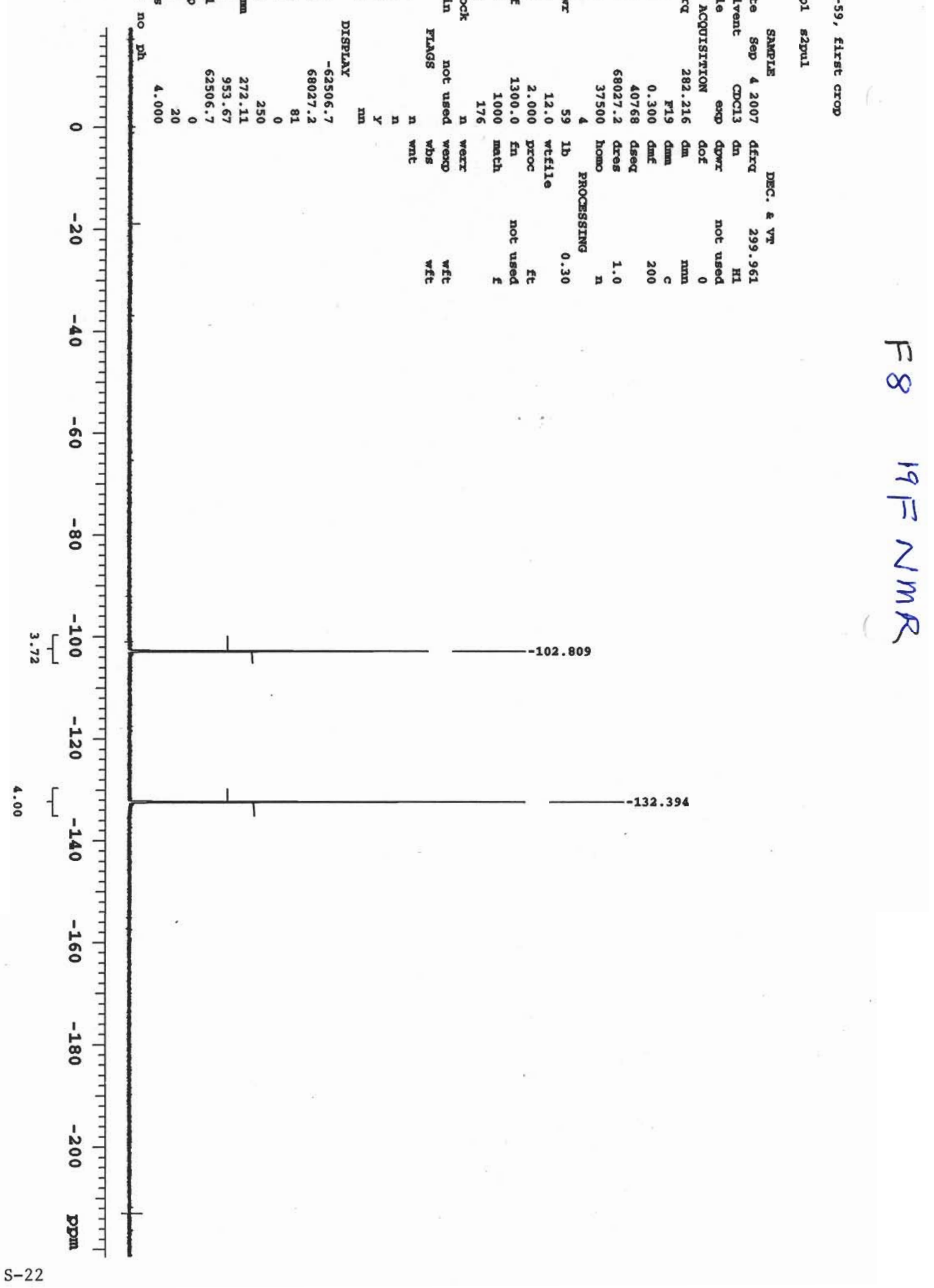




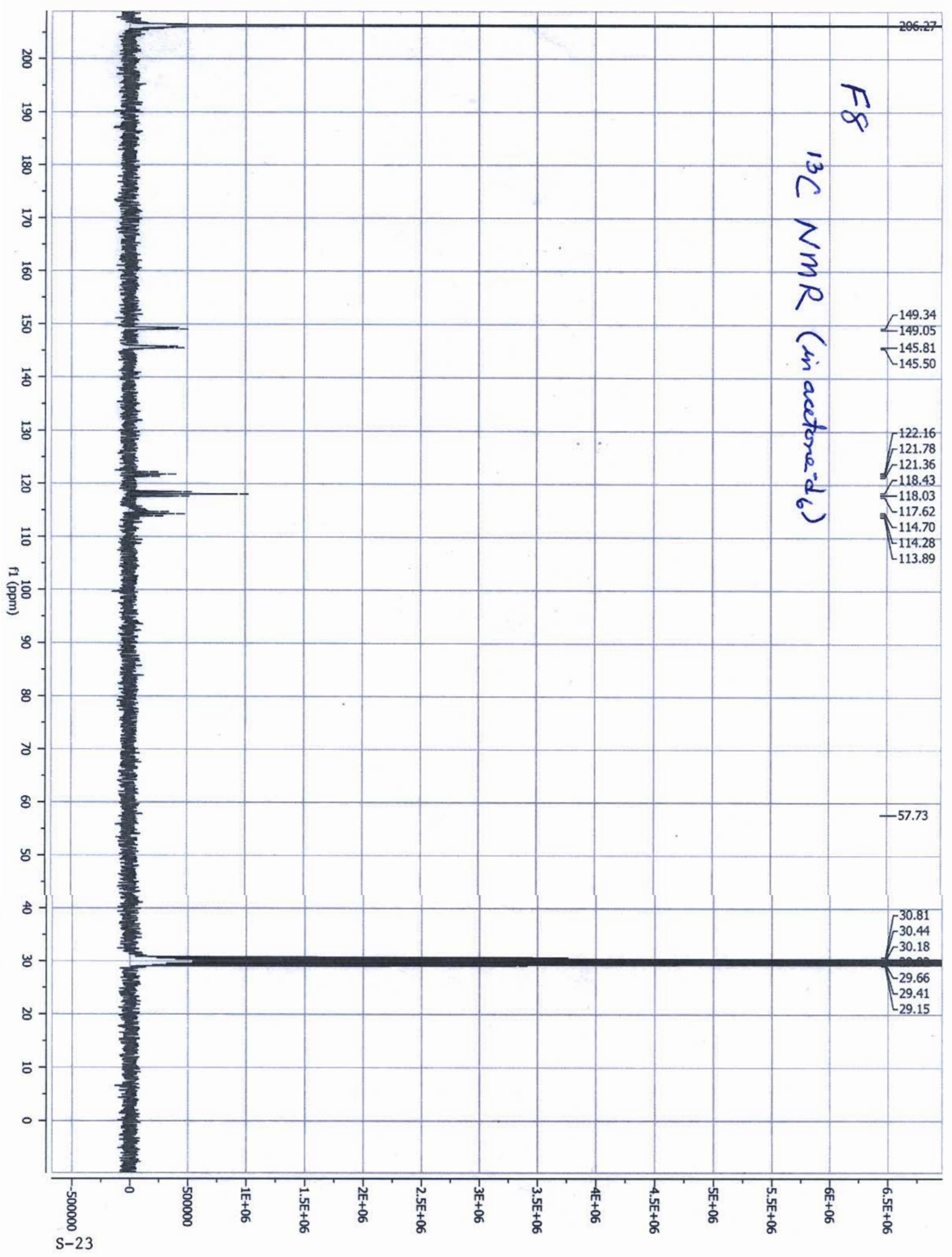




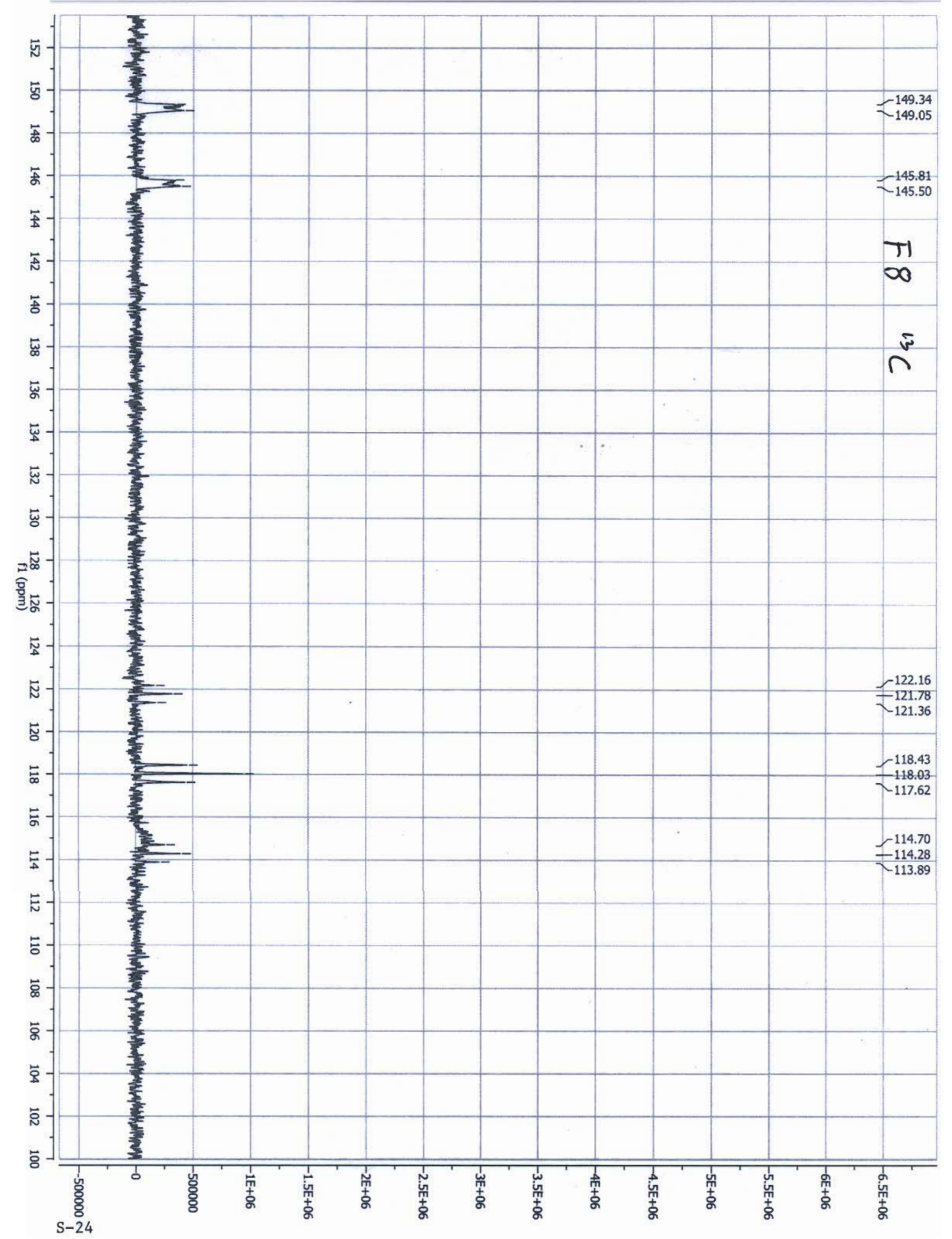

